\title{
ROLE OF PLAIN RADIOGRAPHS IN EVALUATION OF RADIOPAQUE FOREIGN BODIES IN GASTROINTESTINAL TRACT
}

\author{
Flora Juanita Edwin ${ }^{1}$, Arun Chelladurai ${ }^{2}$ \\ ${ }^{1}$ Associate Professor, Department of Radiodiagnosis, Government Thoothukudi Medical College. \\ ${ }^{2}$ Associate Professor Department of Radiodiagnosis, Government Thoothukudi Medical College.
}

\begin{abstract}
BACKGROUND

Foreign bodies in gastrointestinal tract is clinically a serious condition with associated risks for morbidity and mortality. Commonly found objects include coins, fish bones, chicken bones, pieces of glass, dental prosthesis, batteries and needles. The goals of initial assessment are to identify the type of object and its location in the gastrointestinal tract. Plain radiographs helps in the localisation of radiopaque foreign bodies and in assessing the type of foreign body. Aim of the study is to evaluate the usefulness of plain radiographs in the evaluation of foreign bodies in gastrointestinal tract.
\end{abstract}

\section{MATERIALS AND METHODS}

The study is a retrospective study of 30 cases from February 2016 to July 2016 in the age group 1 to 65 years who presented in the emergency department with the history of radiopaque foreign body ingestion or insertion. Plain radiographs were taken for the patients for assessing the location and type of foreign body.

\section{RESULTS}

Of the 30 cases, coins were the commonest foreign body ingested with 14 cases. 5 cases were fish bone ingestion, 3 cases were safety pins, 3 cases were dentures and dental wires, 2 cases were chicken bone, 1 case was pendant, 1 case was glass piece and 1 case was bathroom faucet. The foreign bodies were mostly located in the stomach ( 10 out of 30 cases). Retropharyngeal air was seen in one of the cases indicating perforation of pharynx by the foreign body.

\section{CONCLUSIONS}

The study concluded that plain radiographs are helpful in identifying the type of radiopaque foreign body and in the localisation of foreign body in the gastrointestinal tract. Complications of foreign body ingestion like perforation can also be diagnosed in plain radiographs. The study also concluded that plain radiographs are useful in following the foreign body in gastrointestinal tract and also in giving a road map to the surgeons for the management of the foreign body in the gastrointestinal tract.

\section{KEYWORDS}

Foreign Body, Radiopaque, Gastrointestinal Tract, Localisation.

HOW TO CITE THIS ARTICLE: Edwin FJ, Chelladurai A. Role of plain radiographs in evaluation of radiopaque foreign bodies in gastrointestinal tract. J. Evolution Med. Dent. Sci. 2016;5(80):5947-5949, DOI: 10.14260/jemds/2016/1343

\section{BACKGROUND}

Foreign bodies in gastrointestinal tract (GIT) is clinically a serious condition with associated risks for morbidity and mortality. Almost $80 \%$ of cases are in early childhood ( 2 to 4 years) with majority of cases resulting from swallowing coins. Commonly found objects include coins, fish bones, chicken bones, pieces of glass, dental prosthesis, batteries and needles. The ingestion of foreign bodies in adults is accidental and is commonly fish or chicken bone ingestion. Almost 80 to $90 \%$ of foreign bodies pass freely from GIT without any complication. 10 to $20 \%$ will require endoscopic removal and only $1 \%$ will require surgery. The goals of initial assessment are to identify the type of object and its location in the gastrointestinal tract. Plain radiograph helps in the localisation of foreign body and in assessing the type of foreign body. ${ }^{1}$

Financial or Other, Competing Interest: None.

Submission 22-08-2016, Peer Review 17-09-2016,

Acceptance 22-09-2016, Published 04-10-2016.

Corresponding Author:

Dr. Flora Juanita Edwin,

Associate Professor,

Department of Radiodiagnosis,

Government Thoothukudi Medical College Hospital,

Thoothukudi-628001, Tamilnadu.

E-mail: eflorajuanita@yahoo.in

DOI: $10.14260 /$ jemds $/ 2016 / 1343$

\section{AIM OF THE STUDY}

Aim of the study is to evaluate the usefulness of plain radiographs in the diagnosis and localisation of foreign bodies in the gastrointestinal tract. The study is also used to assess the types of foreign body ingested or inserted into the gastrointestinal tract.

\section{MATERIALS AND METHODS}

The study is a retrospective study of 30 cases between February 2016 to July 2016 in the age group 1 to 65 years who presented in the emergency department with history of accidental radiopaque foreign body ingestion or insertion. Out of the 30 cases, 14 were male and 16 were female patients. Plain radiographs were taken for all patients for assessing the location and type of foreign body. Both AP and lateral views are necessary as some radiopaque foreign bodies overlying vertebral column may be visible only in lateral view. The radiographs taken are plain radiographs of neck, chest and abdomen.

\section{RESULTS}

Of the 30 cases, coins were the commonest foreign bodies ingested with 14 cases. 5 cases were fish bone ingestion, 3 cases were safety pins, 3 cases were dentures and dental wires, 2 cases were chicken bone, 1 case was pendant, 1 case was glass piece and 1 case was bathroom faucet (Table 1). 
The foreign bodies were mostly located in the stomach $(10$ out of 30 cases), 2 foreign bodies were located in nasopharynx, 7 foreign bodies were located in oropharynx, 6 foreign bodies were in the oesophagus, 4 foreign bodies were in the colon and 1 the rectum (Table 2).

\begin{tabular}{|c|c|}
\hline Foreign body type & $\mathbf{n} \%$ \\
\hline Coin & $47(14)$ \\
\hline Fish Bone & $17(5)$ \\
\hline Safety Pin & $10(3)$ \\
\hline Dentures & $10(3)$ \\
\hline Chicken Bone & $7(2)$ \\
\hline Pendant & $3(1)$ \\
\hline Glass Pieces & $3(1)$ \\
\hline Faucet & $3(1)$ \\
\hline Table 1: Types of Foreign Bodies (n=100)
\end{tabular}

\begin{tabular}{|c|c|}
\hline Foreign Body Location & $\mathbf{n} \%$ \\
\hline Nasopharynx & $7(2)$ \\
\hline Oropharynx & $23(7)$ \\
\hline Oesophagus & $20(6)$ \\
\hline Stomach & $33(10)$ \\
\hline Colon & $14(4)$ \\
\hline Rectum & $3(1)$ \\
\hline Table 2: Location of Foreign Bodies (n=100) \\
\hline
\end{tabular}

With this initial information, the cases were followed with serial radiographs. 25 out of the 30 foreign bodies passed out of the gastrointestinal tract spontaneously. 4 cases of fish bone located in oropharynx required endoscopic removal.(2) The case of accidental insertion of faucet into the rectum required surgical intervention as two-staged procedure. The faucet has perforated the rectum and emergency colostomy was done for the patient to allow the rectal perforation to heal. Revision and closure of the colostomy was done at a later date.

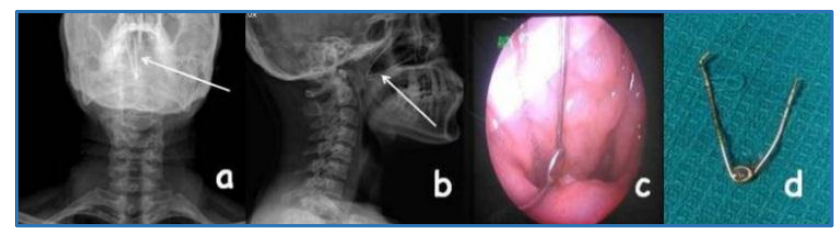

Fig. 1(a) \& (b): Plain Radiograph of Neck AP and Lateral View shows an open Safety Pin in Nasopharynx, (c) Endoscopic View of the Safety Pin, (d) Safety Pin after Removal

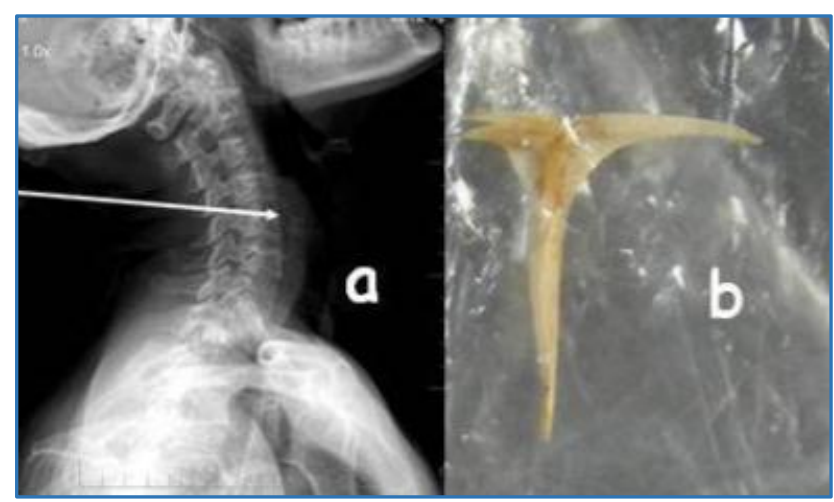

Fig. 2 (a): Plain Radiograph of Neck Lateral view shows a Fish Bone in Oropharynx, (b) Fish Bone after Removal

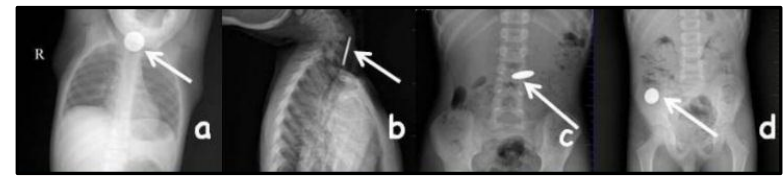

Fig. 3 (a) \& (b) Plain Radiograph of Neck AP and Lateral view shows Coin in Cricopharynx (c) \& (d) Plain Radiograph of Stomach shows Coin in Stomach-and Colon respectively

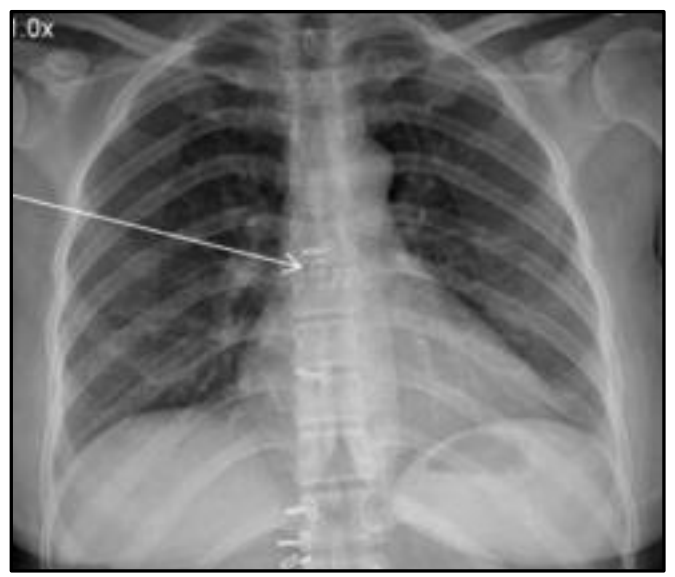

Fig. 4: Plain Radiograph of Chest AP view Dentures in Oesophagus

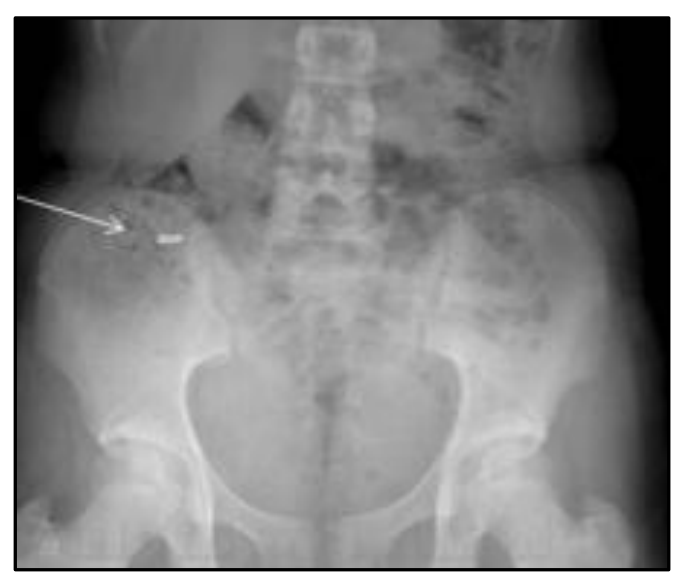

Fig. 5: Plain Radiograph of Abdomen AP view shows Pendant in Colon

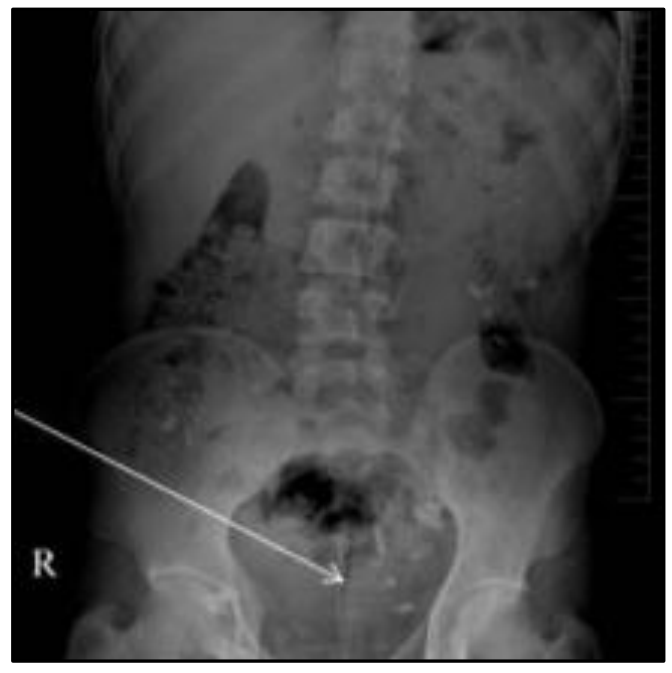

Fig. 6: Plain Radiograph of Abdomen AP view shows Glass Pieces in Colon 


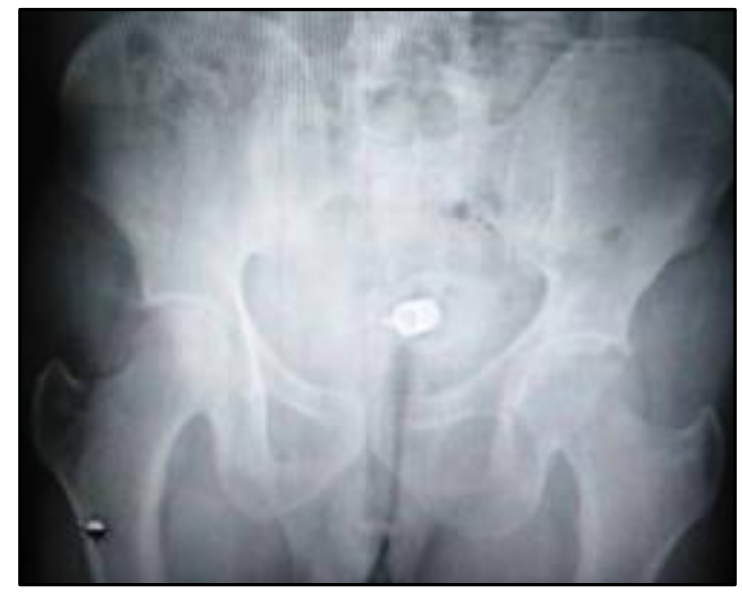

Fig. 7: Plain Radiograph of Abdomen AP view shows Faucet in Rectum

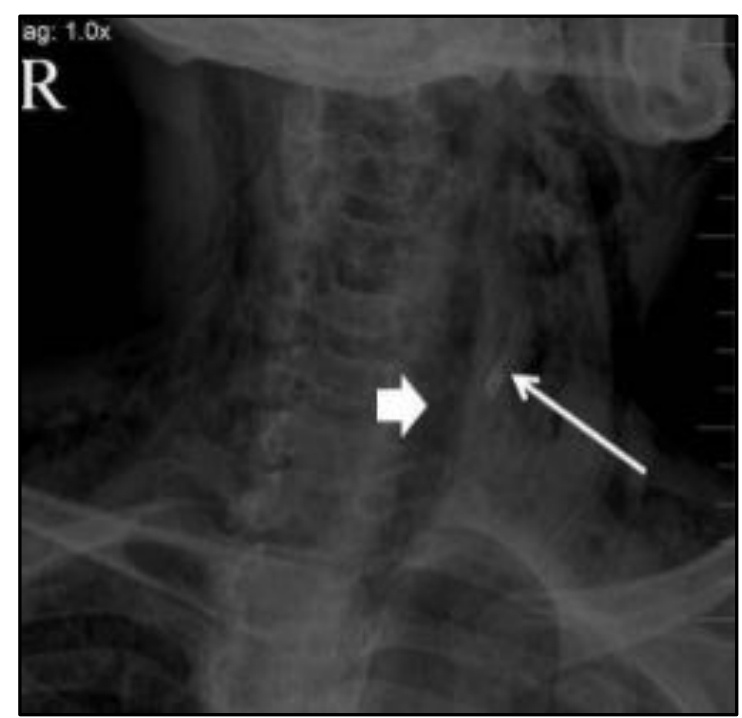

Fig. 8: Plain Radiograph of Neck Lateral view shows Chicken Bone in Cricopharynx (Arrow). Air is seen in Retropharyngeal Space (Arrow head) suggestive of Perforation

\section{DISCUSSION}

Clinical history of the patients is very important in the diagnosis of foreign bodies in the GIT Patients usually present with the complaints of difficulty in swallowing during eating, foreign body sensation in the throat, chest pain, abdominal pain, vomiting and haematemesis.

In our study with the history of accidental foreign body ingestion or insertion, we identified coins, fish bones, chicken bones, safety pin, pieces of glass, pendant, dental prosthesis and bathroom faucet in the plain radiographs (Figures 1 to 8). Almost $80 \%$ of cases are in early childhood ( 2 to 4 years) with majority of cases resulting from swallowing coins (Figure 3 ). The ingestion of foreign bodies in adults is commonly accidental and is commonly fish or chicken bone ingestion.

The first imaging investigation done in patients with the history of foreign body insertion is plain radiograph. The chances of picking up a foreign body in plain radiograph depends on its radio opacity.
Serial radiographs are used to determine the passage of the foreign body and the complications resulting from it. Foreign bodies in GIT are usually treated conservatively.

Almost 80 to $90 \%$ of foreign bodies pass freely from GIT without any complication. 10 to $20 \%$ will require endoscopic removal(3) and $1 \%$ will require surgery.

The most common complication of foreign body ingestion is perforation. Retropharyngeal air (Figure 8), pneumomediastinum and pneumoperitoneum are seen in plain radiographs in cases of foreign body perforation of the GIT. $(4,5,6)$ In cases of perforation of GIT by foreign body management is by emergency surgery. In our study, there was no mortality.

CT scan may be done in cases where plain radiographs are inconclusive. $(7,8$,

\section{CONCLUSION}

Plain radiographs are helpful in identifying the type of radiopaque foreign body and in the localisation of foreign body in the gastrointestinal tract. Complications of foreign body ingestion like perforation can also be diagnosed in plain radiographs. The study also concluded that plain radiographs are useful in following the foreign body in gastrointestinal tract and also in giving a road map to the surgeons for the management of foreign body in the gastrointestinal tract.

\section{ACKNOWLEDGEMENTS}

The authors would like to thank Mr. Mariappan for his contribution in images and data collection.

\section{REFERENCES}

1. Pinto A, Scaglione M, Pinto F, et al. Tracheobronchial aspiration of foreign bodies: current indications for emergency plain chest radiography. Radiol Med 2006;111(4):497-506.

2. Smith MT, Wong RK. Foreign bodies. Gastrointest Endosc Clin N Am 2007;17(2):361-82.

3. Mosca S, Manes G, Martino R, et al. Endoscopic management of foreign bodies in the upper gastrointestinal tract: report on a series of 414 adult patients. Endoscopy 2001;33(8):692-6.

4. Virk JS, Pang J, Okhovat S, et al. Analysing lateral soft tissue neck radiographs. Emerg Radiol 2012;19(3):255-60.

5. Craig FW, Schunk JE. Retropharyngeal abscess in children: clinical presentation, utility of imaging, and current management. Pediatrics 2003;111(6 Pt 1):1394-8.

6. De Lucas EM, Ruiz-Delgado ML, García-Barón PL, et al. Foreign esophageal body impaction: multimodality imaging diagnosis. Emerg Radiol 2004;10(4):216-7.

7. De Lucas ME, Sádaba P, Garcia-Barón LP, et al. Value of helical computed tomography in the management of upper esophageal foreign bodies. Acta Radiol 2004;45(4): 369-74.

8. Tiago RS, Salgado DC, Correa JP, et al. Foreign body in ear, nose and oropharynx: experience from a tertiary hospital. Braz J Otorhinolaryngol 2006;72(2):177-81. 